\title{
Três formas diferentes de ler Tiago Rodrigues
}

\author{
Luís Mestre
}

Tiago Rodrigues, Três dedos abaixo do joelho / Tristeza e alegria na vida das girafas / Coro dos amantes, Posfácio de Fernando Matos Oliveira, Coimbra, Imprensa da Universidade de Coimbra, 2013, 120 pp.

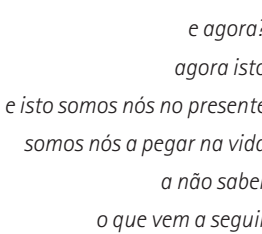

Tiago Rodrigues Coro dos amantes

Tiago Rodrigues, actor, dramaturgo, produtor, encenador, fundador e director artístico do Mundo Perfeito - estrutura que criou em 2003 com Magda Bizarro - é um dos artistas mais ecléticos do nosso país. Recentemente, o jornal Público considerou Rodrigues um dos mais influentes jovens criadores da última década em Portugal. É num volume publicado pela Imprensa da Universidade de Coimbra, assinalando em livro o projecto "dramaturgo residente", associado ao Teatro Académico Gil Vicente em Coimbra, que podemos encontrar três textos seus, criados em três momentos diferentes de escrita.

Em Coro dos amantes (2007), Tiago Rodrigues revisita uma peça breve que escreveu e estreou em 2006, no Teatro Maria Matos, com um título mais longo: Coro dos amantes a caminho do hospital. A versão de 2007 é mais longa e optimista e inclui uma interessante alteração na forma: em vez de dividir o texto em actos e cenas, são canções, interpretadas por um coro, que organizam a sequência desta peça. 0 casal referido na peça tem uma simples e curta indicação de caracterização: "Ele" e "Ela". Para além do género das personagens, não existe qualquer indicação cénica: estamos perante duas entidades descaracterizadas, dois seres anónimos. Neste texto, Rodrigues acolhe abertamente a coralidade e logo na primeira linha de diálogo somos atingidos por palavras directas que têm por objectivo criar uma empatia com estas personagens: "Ele" e "Ela" recitam dirigindo-se a nós, leitores, e só muito raramente à outra personagem em cena. Temos sempre duas visões do mesmo momento, da mesma viagem. $\mathrm{E}$ quando por instantes as duas personagens se confrontam voltam-se para nós muito rapidamente, usando de novo a terceira pessoa, como se fosse inevitável a presença de

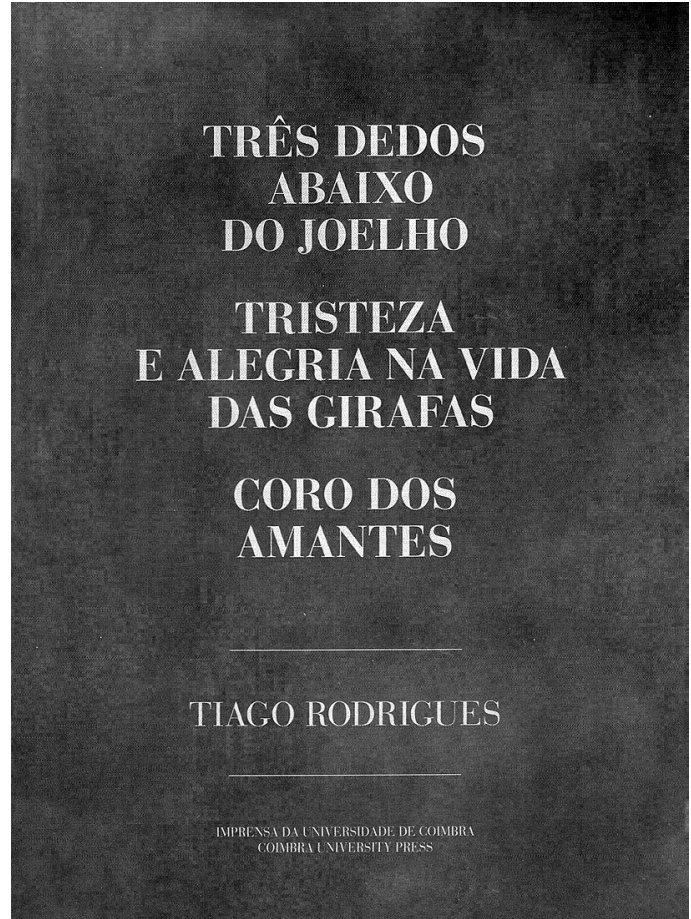

um ouvinte, ou de vários, no seu diálogo interior, um ouvinte não-participante nessa noite quase fatal. Mas qual é a história que esta canção transporta? Nesta viagem de urgência ao hospital "Ela" encontra-se entre a vida e a morte. Esta jornada (quase) fatal provoca no casal um turbilhão de memórias, emoções e sentimentos. Podemos constatar que a ideia base da peça é um cliché: a vida passa à nossa frente quando estamos a perdê-la. Mas o autor desvia-se desse mesmo cliché através da forma e do veículo que criou para contar a história de duas personagens banais e anónimas. 0 texto de Rodrigues é uma constante reflexão de um casal sobre a sua vida envolta em banalidades, tempo perdido e frustrações. Em alguns momentos podemos perceber que é a voz do autor que é veiculada através da voz das personagens com o recurso à polifonia:

ELA: tanto tempo perdido / a fazer pequenas coisas / pequenas coisas sem importância / a ver os noticiários / a ler os jornais / a tomar cafés / a enviar facturas / a escrever mails / a falar ao telefone / a agrafar papéis / a tocar às campainhas / a bater às portas / a falar sobre teatro / a escrever projectos de teatro / a arranjar dinheiro para fazer teatro / a queixar-me de não me darem dinheiro para fazer teatro / a tentar 


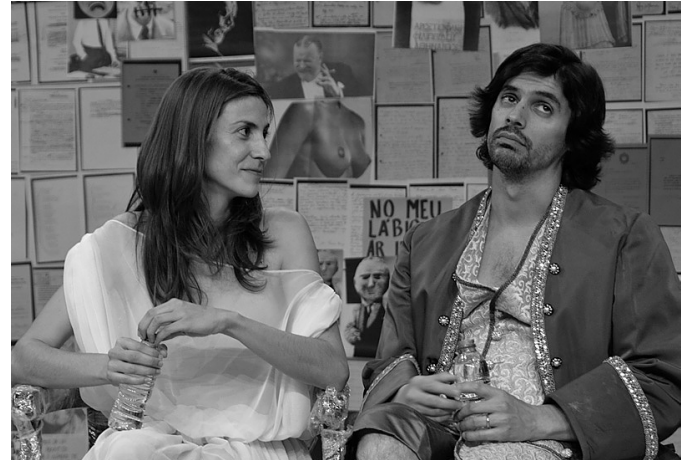

fazer teatro / a não conseguir fazer teatro / tanto tempo desperdiçado / e agora não tenho tempo / para chegar ao hospital. (p. 89)

Estas personagens em Paixão, revelam uma enorme frustração e sentido de culpa quando são confrontadas com o tema da morte: percebem que as suas vidas são levianas, cheias de inércia. À medida que relatam o acontecimento trágico, as personagens-testemunha distanciam-se mimando a separação física dessa noite terrivel.

Podemos verificar na segunda canção que o casal se dispersa mais ainda e que cada personagem segue o seu próprio rumo. A sincronia de vozes torna-se cada vez mais rara. Rodrigues usa, num vaivém constante, alusões a Scarface', filme a que o casal assistia na noite fatídica, como se espectros dessa mesma película estivessem na memória, na retina, e por vezes nas acções deste casal. Numa evidente rapsodização, os diálogos e acções do filme são utilizados e recriados pelo casal, promovendo uma proximidade entre cinema e teatro. Por vezes "Ele" transforma-se em Al Pacino num jogo partilhado com "Ela":

ELA: A disparar a disparar / os assassinos tentam entrar na mansão / e o al pacino a disparar / a gritar em inglês com sotaque cubano a saber que vai morrer / mas há-de levar alguns com ele / ele é um animal ferido e dispara / dispara dispara e já não é o al pacino / é ele eu sonho com ele / a cara dele no corpo do al pacino / ele de metralhadora em punho / a entrar pelo hospital / a invadir o reino dos mortos. (pp. 97-98)

Após o perigo, os amantes encontram-se em casa onde voltam à banalidade, aos pequenos atritos do dia-a-dia e às discussões. Em perda irremediável de si mesmas, presenciando a sua banal existência e o regresso ao

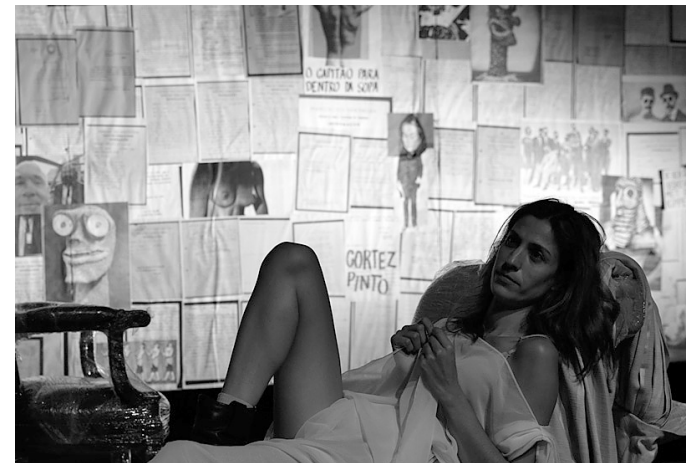

Três dedos abaixo do

joelho,

texto e enc. Tiago

Rodrigues,

Mundo Perfeito, 2012

(< Isabel Abreu

e Gonçalo Waddington; $>$ Isabel Abreu),

fot. Magda Bizarro.

Purgatório, as personagens elaboram individualmente projectos de grandes acções, mas que não passarão de desejos, pois a inércia regressará. Numa repetição-variação, assistimos ao momento em que visualizam Scarface noite dentro e, tal como da primeira vez, são vencidos pelo sono e adormecem antes do final do filme.

Tristeza e alegria na vida das girafas (2011) é sobre uma criança e a sua demanda para realizar um trabalho escolar. E para o fazer precisa de dinheiro para pagar a mensalidade da televisão por cabo para poder ver o documentário A vida das girafas no Discovery Channel. A missão desta jovem consiste numa ação completamente banal e que nada tem de épico. Aliás, esta personagem pode ser qualquer aluna, de uma qualquer escola, de uma qualquer familia, na qual o pai não tem dinheiro para pagar a televisão por cabo. A identidade e o objectivo são assumidos pela própria personagem logo no início do texto:

GIRAFA: Encontro-me na ocasião de apresentar um trabalho escolar intitulado "Tristeza e alegria na vida das girafas". Espero que retirem prazer do visionamento deste trabalho e que não possuam aborrecimento. Um trabalho escolar é uma investigação que um ou mais alunos produzem para apresentar no interior da escola. A escola é o edificio onde as crianças consomem educação. Educação é uma orquestra de regras para o desenvolvimento do corpo e do espirito. [...] A idade que eu possuo é nove anos, um mês e doze dias, a contar do momento em que eu nasci, incluindo os anos bissextos. Sou, portanto, uma criança. Uma criança é a versão minima de uma pessoa. (p. 35)

Rodrigues cria uma infratextualidade onde o nome e o objecto de estudo são exactamente o mesmo e determina o verdadeiro objectivo da viagem desta criança: a descoberta por si mesma e o seu amadurecimento com a passagem para a puberdade ou pré-adolescência. Girafa escreve 0
${ }^{1}$ Scarface é um filme realizado por Brian de Palma em 1983, com argumento de Oliver Stone a partir dum romance de Armitage Trail. Emblemático da cinematografia hollywoodesca daquela década, narra o mundo violento em que um imigrante cubano tenta formar um império de tráfico de drogas. 


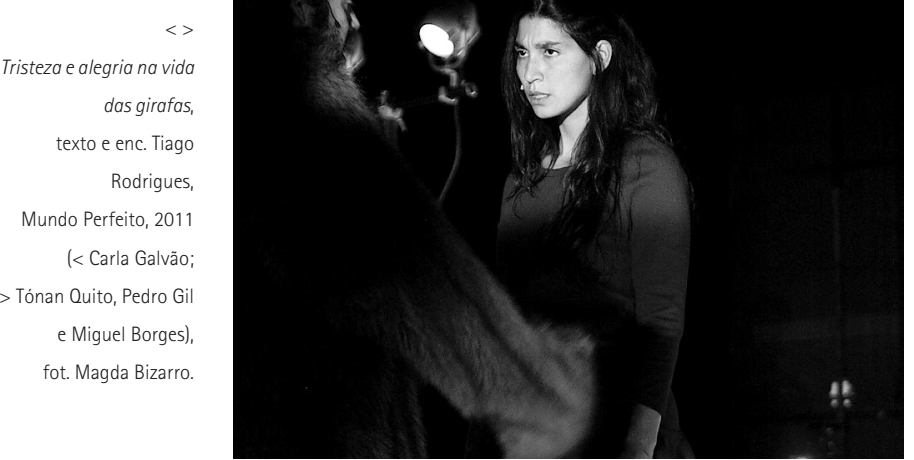

seu trabalho escolar com o leitor onde, aparentemente, tudo o que a envolve - inclusivamente as outras personagens - é produto seu. Tal como Rodrigues nos tem habituado, as indicações cénicas são raras ou mesmo inexistentes. No entanto, aqui o autor opta por uma inovação no sentido de manter essa mesma rarefacção. Como referimos, a Girafa participa e narra, como se escrevesse o seu trabalho e, usando essa característica, Rodrigues torna-a num veículo de indicações cénicas, a nivel de ações e de aspetos técnicos:

GIRAFA: [...] Isto sou eu a reparar numa loja onde vendem esferovite que parece uma casa cheia de neve. [...] Isto sou eu a reparar que há pedras pretas no chão encaixadas entre as pedras brancas a formar desenhos de barcos e gaivotas. [...] Este é o som da minha alegria no recreio da escola. Este é o som da tristeza do homem que é meu pa a ver-me brincar no recreio da escola. [... Este é o som da rua. As ruas não existem na natureza: são fabricadas pela espécie humana para facilitar a locomoção. (pp. 37 e 57)

Desta forma o autor mantém a dinâmica textual, não a comprometendo com a inclusão de didascálias.

Nesta sua longa viagem da Girafa pela pólis, é-nos revelado o triângulo eu-casa-mundo. Rodrigues propõe um texto onde nos mostra as dinâmicas, as relações, as irracionalidades e as contradições do mundo aos olhos de uma criança, demonstrando a sua capacidade de expor a intimidade das personagens no espaço público e enveredando, à semelhança de Coro dos maus alunos (2009), por um teatro político.

Já na assumida colagem Três dedos abaixo do joelho (2012), Rodrigues revela-nos a sua mestria em tomar como sua a memória de outros. E como? Pela apropriação e manipulação, sem receios. Fernando Matos de Oliveira, autor do posfácio, descreve este tempo de escrita da seguinte forma:

Há algo de perverso e inédito na proposta, porque se trata de escrever com as mesmas palavras que silenciaram a escrita. (Matos Oliveira in Ibid.: 117)

0 constante movimento na escrita de Rodrigues proporciona-nos um diálogo com partes muito distintas: o discurso dos censores com a prática teatral e a reunião de textos censurados de vários autores, levando-nos para uma narrativa onde várias forças se confrontam em fronteiras pouco definidas. 0 autor-colador proporcionanos um jogo subversivo.

A constante inquietação de Rodrigues por algo novo, vivo, com sangue a correr, único, é visivel nestas três obras

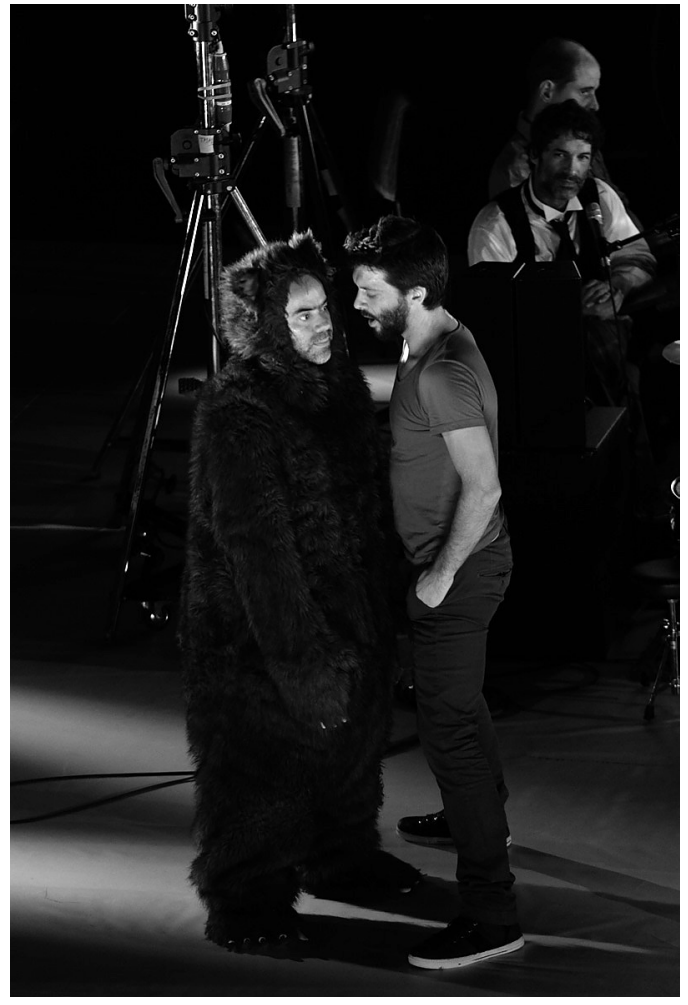

separadas por cinco anos. Os veículos que transportam estas histórias são variados e diferentes entre si. Percebemos que este autor tem uma forte preocupação com a forma. Recordemos as palavras de Sarrazac:

0 dramaturgo quer criar obra nova, alimentando-se generosamente desta memória obscura das formas, coloca-as em tensão, e junta-as numa espécie de mosaico. (Sarrazac 2002: 179)

É o caso de Tiago Rodrigues. Encontramos também uma tendência rapsódica que implica alterações profundas na linguagem, na categoria teatral, na fábula, no fait-divers e nos vasos comunicantes com outras formas de arte (o cinema, por exemplo). Esta mestiçagem, este rompimento com a estrutura hermética e fechada, cria novos pontos de fuga que nos surpreendem constantemente. Nos textos de Rodrigues existe uma constante alteração, ou, melhor dizendo, procura de novos conteúdos e linguagens a nivel dramático. Aliás, esta é uma das suas características mais fortes: o desprendimento das regras, das convenções, dos títulos e das catalogações.

Rodrigues é um autor com uma enorme versatilidade e um transgressor no que diz respeito ao conteúdo e à forma, o que lhe confere uma hibridez na escrita. Não será de todo descabido confirmar que este autor é já uma das referências no panorama teatral nacional, e que o trabalho que tem desenvolvido é, sem dúvida, um dos mais interessantes no nosso país.

\section{Referências bibliográficas}

RODRIGUES, Tiago (2009), "Coro dos maus alunos" in AA.W., PANOS: Palcos novos palavras novas, Lisboa, Edições Cotovia.

SARRAZAC, Jean-Pierre (2002), o futuro do drama, [ed. francesa -1999] trad. Alexandra Moreira da Silva, Porto, Campo das Letras. 